\title{
A retrospective discussion of the prognostic value of combining prothrombin time(PT) and fibrinogen(Fbg) in patients with Hepatocellular carcinoma
}

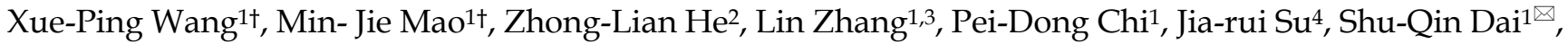 \\ Wan-Li Liu ${ }^{\boxplus}$ \\ 1. Department of Laboratory Medicine, State Key Laboratory of Oncology in South China, Collaborative Innovation Center for Cancer Medicine, Sun Yat-sen \\ University Cancer Center, Guangzhou, 510060, China \\ 2. Department of Information section, State Key Laboratory of Oncology in South China, Collaborative Innovation Center for Cancer Medicine, Sun Yat-sen \\ University Cancer Center, Guangzhou, 510060, China \\ 3. Guangdong Esophageal Cancer Institute \\ 4. Guangdong Medical University, 523808, China. \\ tEqual contributors
}

$\triangle$ Corresponding authors: Wan-Li Liu and Shu-Qin Dai, Sun Yat-sen University Cancer Center, 651 Dongfeng Road East, Guangzhou 510060, P. R. China. Address: Department of Laboratory Medicine, Sun Yat-sen University Cancer Center, 651 Dongfeng Road East, Guangzhou 510060, P. R. China. Tel.: +86-20-87343196 Fax: +86-20-87343196 Email: liuw1@sysucc.org.cn daishq@sysucc.org.cn

(c) Ivyspring International Publisher. This is an open access article distributed under the terms of the Creative Commons Attribution (CC BY-NC) license (https://creativecommons.org/licenses/by-nc/4.0/). See http://ivyspring.com/terms for full terms and conditions.

Received: 2017.01.14; Accepted: 2017.04.08; Published: 2017.07.05

\begin{abstract}
Aims: The levels of coagulation system tests have been studied in various cancers. In this study, our aim is to evaluate the prognostic value of pretreatment plasma coagulation tests in hepatocellular carcinoma (HCC) patients.

Patient and methods: A retrospective study was performed in 539 patients with HCC, and follow-up period was at least 60 months until recurrence or death. The prognostic significance of coagulation system tests (prothrombin time, activated partial thromboplastin time, thrombin time, fibrinogen) were determined by univariate and multivariate Cox hazard models. Then, according to the results of the multivariate analyses, we proposed the coagulation-Based Stage, which combined the independent risk factors (prothrombin time and fibrinogen).

Results: Coagulation system tests including prothrombin time (PT), activated partial thromboplastin time (APTT), thrombin time (TT), fibrinogen (Fbg) were analyzed. Patients with prolonged PT $(\geq 12.1 \mathrm{sec})$ levels had significantly poor overall survival $(\mathrm{OS})$ and disease-free survival (DFS), not only in the entire cohort (HR: $1.661,95 \% \mathrm{Cl}: 1.125-2.451, p=0.011$ vs. HR: $1.660,95 \% \mathrm{Cl}: 1.125-2.451, p=0.011)$, but also in the subgroups stratified by pathological stage (stage I-II and stage III-IV). Additionally, high Fbg ( $\geq 2.83 \mathrm{~g} / \mathrm{L})$ levels experienced significantly decreased OS and DFS (HR: 2.158, 95\% Cl: 1.427-3.263, $p<0.001$ vs. HR: $2.161,95 \% \mathrm{Cl}$ : 1.429-3.267, $p<0.001$ ), not only in the entire cohort but also in the subgroups stratified by pathological stage (stage I-II and stage III-IV). All the patients were then stratified (based on combined PT and Fbg) into three groups, The OS for HCC patients were $(41.37 \pm 17.76)$, $(31.83 \pm 19.84)$ and $(18.68 \pm 18.41)$ months, and the DFS for HCC patients were $(41.15 \pm 17.88)$, $(31.65 \pm 19.81)$ and $(18.66 \pm 18.39)$ months.

Conclusions: Our findings suggest that the combination of plasma PT and Fbg levels should be evaluated as the valuable predictor of survival in patients with HCC.
\end{abstract}

Key words: HCC, prothrombin time, fibrinogen, prognosis, overall survival, disease-free survival 


\section{Introduction}

Hepatocellular carcinoma (HCC) is one of the most common malignancies and the third most frequent cause of cancer-related death worldwide [1]. More than half of the patients with HCC are diagnosed in China. In the past several decades, substantial developments and advances have been made in the screening, diagnosis and staging, especially the improvement of imaging techniques. However, in the worldwide, the 5-year overall survival (OS) rate of HCC is only 7\% [2]. To date, many serum biomarkers, such as a-fetoprotein (AFP), $\gamma$-glutamyl transferase (GGT), and (carcino-embryonic antigen) $\mathrm{CEA}$, have been used to predict the survival of HCC patents [3, 4]. Especially, AFP is the widely used tumor biomarker for HCC prognosis. However, due to limited sensitivity and specificity, these markers are not entirely reliable. Thus, more effective biomarkers are needed to identify the biological characteristics and guide individualized comprehensive treatments of HCC to improve patient survival.

The association between cancer and the coagulation system is well recognized [5]. Importantly, cancer-induced hemostatic activity has been shown to promote tumor development, progression and metastasis [6-8]. In fact, abnormal coagulation parameters that represent hemostatic and fibrinolytic systems have been associated with tumor progression and dissemination, which could decrease overall survival (OS) of tumors [9]. In our previous study, the decreased pre-treatment thrombin time (TT) was reported to be associated with the shorter ESCC survival [10]. Research was conducted by Tas et al. [11], who reported the prognostic values of the prothrombin time (PT) and international normalized ratio (INR) in lung cancer. Moreover, in the original studies, hyperfibrinogenemia was also identified as independent prognostic predictors in melanoma [12] and gallbladder cancer [13]. The liver plays an important role in the metabolism and synthesis of clotting factors, which could regulate the blood coagulation and anticoagulation system. The ability to synthesize clotting factors and anticoagulation proteins is damaged by various liver diseases, such as hepatitis, liver cirrhosis and HCC [13]. Furthermore, the patients in advanced HCC often have abnormal coagulation, involving coagulation, fibrinolysis and other complex pathological changes, which is closely related to the tumor progression, the prognosis and survival of cancer patients. Prothrombin time (PT), activated partial thromboplastin time (APTT), thrombin time (TT), fibrinogen (Fbg) are the most common coagulation tests used in the laboratory, but few studies focused on the prognostic value in cancer. Therefore, there is little evidence about the impact on hemostatic system in clinical outcomes with HCC patients.

Given this, we aim to elucidate a retrospective cohort analysis to examine the association between PT, Fbg, overall survival (OS) and disease-freesurvival (DFS) in HCC patients.

\section{Methods}

\section{Patients}

A total of 539 eligible patients, who received histologically confirmed diagnosed with HCC between January 2009 and December 2012 at the Sun Yat-sen University Cancer Center were collected and enrolled into this retrospective study. The demographic details are described in Table 1. All of the patients met the diagnostic criteria for HCC. Cancer staging was based on the American Joint Committee on Cancer Staging system (AJCC, 2002; Greene, American Joint Committee on Cancer., American Cancer Society, 2002). Exclusion criteria were as follows: (1) patients treated with surgery or received any antitumor treatment drugs before plasma collection; (2) patients who regularly took procoagulant or anticoagulant therapy or took blood transfusions within 1 month of study onset; (4) patients with concomitant diseases associated with influenced plasma coagulation levels (i.e., VTE, pulmonary embolism, or disseminated intravascular coagulation (DIC) within 1 month of study onset or during the subsequent treatment); (5) other types of malignancy. All patients received treatment. Clinical information, including demographic data, pathological tumor node metastasis (pTNM) stage, alcohol consumption, BMI, family history of cancer, overall survival (OS) and disease-free survival (DFS) data were available for all patients. Prior to use of these plasma, informed consent was obtained from each of the patients. This study was approved by the medical ethics committee of Sun Yat-Sen University Cancer Center (Guangdong, China).

\section{Laboratory Measurements}

As part of the physical examination, peripheral blood was collected in tubes containing sodium citrate prior to the initiation of any treatment to measure coagulation parameters between 7 and $8 \mathrm{am}$, and centrifuged at $3000 \mathrm{r} / \mathrm{min}$ for $10 \mathrm{~min}$ for plasma separation. The levels of PT, APTT, TT and Fbg were 
tested using a Sysmex CA-7000 automatic coagulation analyzer (Sysmex Corporation, Kobe, Japan). All reagents used in this study were provided by kinetic nephelometric detection system using a Diagon Dia-Timer 4 (Diagon Ltd, Budapest, Hungary). The platelet count (PLT) was measured from the blood count using a Sysmex XE-5000 automatic blood-cell counter (Sysmex Corporation, Kobe, Japan)

\section{Follow-up}

After completion of primary treatment, patients were generally followed up every 3 months in the first 2 years, every 6 months for the following 3 to 5 years, and annually thereafter for patients without evidence of recurrence. The last follow-up was in December 2016. The survival status was verified through checking clinical attendance records or direct telecommunication with the patient or their family (performed by The Medical Information Unit in our Cancer Center).

\section{Statistical analysis}

One outcome of our study was OS, which was calculated between the first diagnosis of HCC and death, or the date of the last follow-up. The other outcome was DFS, defined as the time from first diagnosis to the date of disease recurrence. Data were expressed as the mean and standard deviation (mean \pm SD). Continuous variables were categorized using median values as cut-off point. Univariate and multivariate analyses of clinical variables were performed using Cox proportional hazards regression models. The results of this survey were analyzed using the Kaplan-Meier survival curves with the log-rank test and proportional hazard model. The correlation between PT, Fbg and Clinical Characteristics was analyzed using the MannWhitney $U$ test and $\chi^{2}$ test. $P$ values were derived from two-sided tests and $P$ values $<0.05$ were regarded as statistically significant. All statistical tests were performed with SPSS 16.0 for Windows software (SPSS, Chicago, IL, USA).

\section{Results}

\section{Patient Characteristics}

From January 2009 to December 2012, 539 patients with a pathologically confirmed diagnosis of HCC were enrolled in this analysis, and their characteristics are presented in Table 1 . There were 480 men $(89.05 \%)$ and 59 women $(10.95 \%)$, the median age was 53 years (range: 19 to 88 years). Of all patients, the pathological stage of I - II and III-IV were observed in $306(56.77 \%), 233(43.23 \%)$ of the patients, respectively. A total of 409 patients $(75.88 \%)$ had hepatic B virus infection. In the entire cohort of clinical characteristics, pTNM status, tumor size, tumor number, node stage, distant metastases, HBV DNA, AFP, PT and Fbg had influence on OS and DFS of HCC patients.

Table 1. Characteristics and parameters of the HCC patients

\begin{tabular}{|c|c|c|c|c|c|}
\hline Characteristics & no. $(\%)$ & $\begin{array}{l}\text { 5-year OS } \\
\text { (Months) } \\
\text { Mean } \pm \text { SD }\end{array}$ & $\begin{array}{l}p \\
\text { value }\end{array}$ & $\begin{array}{l}5 \text {-year DFS } \\
\text { (Months) } \\
\text { Mean } \pm \text { SD }\end{array}$ & $\begin{array}{l}p \\
\text { value }\end{array}$ \\
\hline \multicolumn{6}{|l|}{ Gender(n) } \\
\hline Male & $480(89.05)$ & $30.82 \pm 20.74$ & 0.524 & $30.65 \pm 20.71$ & 0.566 \\
\hline Female & $59(10.95)$ & $29.71 \pm 20.21$ & & $19.71 \pm 20.21$ & \\
\hline \multicolumn{6}{|l|}{ Age (years) } \\
\hline$\geq 53$ & $275(51.02)$ & $32.05 \pm 20.57$ & 0.167 & $31.75 \pm 20.55$ & 0.226 \\
\hline$<53$ & $264(48.98)$ & $29.30 \pm 20.71$ & & $29.30 \pm 20.71$ & \\
\hline \multicolumn{6}{|l|}{ Stage(n) } \\
\hline I and II & $306(56.77)$ & $38.16 \pm 17.84$ & 0.000 & $37.92 \pm 17.87$ & 0.000 \\
\hline III and IV & $233(43.23)$ & $20.90 \pm 20.06$ & & $20.87 \pm 20.07$ & \\
\hline \multicolumn{6}{|l|}{ Tumor size $(\mathrm{cm})$} \\
\hline$\geq 5$ & $220(40.82)$ & $20.17 \pm 19.68$ & 0.000 & $20.14 \pm 19.69$ & 0.000 \\
\hline$<5$ & $319(59.18)$ & $37.96 \pm 18.06$ & & $37.73 \pm 18.09$ & \\
\hline \multicolumn{6}{|l|}{ Tumor number } \\
\hline Single & $335(62.15)$ & $33.71 \pm 20.02$ & 0.001 & $33.55 \pm 20.04$ & 0.001 \\
\hline Multiple & $192(35.62)$ & $26.74 \pm 20.75$ & & $26.60 \pm 20.66$ & \\
\hline \multicolumn{6}{|l|}{ Node stage } \\
\hline No & $502(93.14)$ & $31.35 \pm 20.34$ & 0.016 & $31.19 \pm 20.32$ & 0.017 \\
\hline $\mathrm{N} 1-2$ & $37(6.86)$ & $21.92 \pm 23.30$ & & $21.92 \pm 23.30$ & \\
\hline \multicolumn{6}{|l|}{$\begin{array}{l}\text { Distant } \\
\text { metastases }\end{array}$} \\
\hline Yes & $31(5.75)$ & $24.52 \pm 23.08$ & 0.102 & $24.52 \pm 23.08$ & 0.108 \\
\hline No & $508(94.25)$ & $31.08 \pm 20.48$ & & $30.92 \pm 20.45$ & \\
\hline \multicolumn{6}{|l|}{ BMI $\left(\mathrm{kg} / \mathrm{m}^{2}\right)$} \\
\hline$\geq 24.0$ & $174(32.28)$ & $32.70 \pm 20.70$ & 0.234 & $32.44 \pm 20.58$ & 0.292 \\
\hline $18.5-23.9$ & $319(59.18)$ & $29.94 \pm 20.74$ & & $29.83 \pm 20.77$ & \\
\hline$<18.5$ & $45(8.35)$ & $28.80 \pm 19.90$ & & $28.80 \pm 19.90$ & \\
\hline \multicolumn{6}{|c|}{ Alcohol behavior } \\
\hline Yes & $200(37.11)$ & $30.02 \pm 21.18$ & 0.683 & $29.66 \pm 21.08$ & 0.535 \\
\hline No & $339(62.89)$ & $31.10 \pm 20.38$ & & $21.08 \pm 20.40$ & \\
\hline \multicolumn{6}{|c|}{$\begin{array}{l}\text { Family history of } \\
\text { cancer }\end{array}$} \\
\hline Yes & $138(25.60)$ & $32.21 \pm 20.52$ & 0.362 & $32.21 \pm 20.52$ & 0.303 \\
\hline No & $401(74.40)$ & $30.18 \pm 20.72$ & & $29.98 \pm 20.68$ & \\
\hline \multicolumn{6}{|l|}{$\begin{array}{l}\text { HBV DNA } \\
\text { (copies/mL) }\end{array}$} \\
\hline$\geq 10^{3}$ & $281(52.13)$ & $30.23 \pm 19.87$ & 0.000 & $30.22 \pm 19.87$ & 0.000 \\
\hline$<10^{3}$ & $128(23.75)$ & $39.98 \pm 18.05$ & & $39.77 \pm 18.05$ & \\
\hline \multicolumn{6}{|l|}{$\operatorname{AFP}(\mathrm{ng} / \mathrm{mL})$} \\
\hline$\geq 400$ & $195(36.18)$ & $24.35 \pm 20.46$ & 0.000 & $24.19 \pm 20.40$ & 0.000 \\
\hline$<400$ & $323(59.53)$ & $35.85 \pm 19.18$ & & $35.70 \pm 19.19$ & \\
\hline \multicolumn{6}{|l|}{ PT(sec) } \\
\hline$\geq 12.1$ & $275(51.02)$ & $25.75 \pm 19.89$ & 0.000 & $25.66 \pm 19.87$ & 0.000 \\
\hline$<12.1$ & $263(48.79)$ & $35.99 \pm 20.17$ & & $35.77 \pm 20.17$ & \\
\hline \multicolumn{6}{|l|}{ APTT(sec) } \\
\hline$\geq 25.6$ & $271(50.28)$ & $27.66 \pm 21.34$ & 0.000 & $27.55 \pm 21.35$ & 0.000 \\
\hline$<25.6$ & $267(49.54)$ & $33.90 \pm 19.47$ & & $33.70 \pm 19.42$ & \\
\hline \multicolumn{6}{|l|}{$\mathrm{Fbg}(\mathrm{g} / \mathrm{L})$} \\
\hline$\geq 2.83$ & $269(49.91)$ & $23.88 \pm 20.43$ & 0.000 & $23.76 \pm 20.33$ & 0 \\
\hline$<2.83$ & $269(49.91)$ & $37.62 \pm 18.51$ & & $37.44 \pm 18.58$ & \\
\hline \multicolumn{6}{|l|}{ TT (sec) } \\
\hline$\geq 18.4$ & $275(51.02)$ & $30.71 \pm 20.57$ & 0.995 & $30.63 \pm 20.52$ & 0.943 \\
\hline$<18.4$ & $263(48.79)$ & $30.80 \pm 20.77$ & & $30.58 \pm 20.78$ & \\
\hline \multicolumn{6}{|l|}{ PLT $\left(10^{9} / \mathrm{L}\right)$} \\
\hline$\geq 178$ & $250(46.38)$ & $26.60 \pm 20.20$ & 0.000 & $26.44 \pm 20.04$ & 0.000 \\
\hline$<178$ & $248(46.01)$ & $34.95 \pm 20.36$ & & $34.78 \pm 20.37$ & \\
\hline
\end{tabular}


Table 2. Univariate and multivariate cox hazards analysis for overall survival in 539 patients with $\mathrm{HCC}$

\begin{tabular}{|c|c|c|c|c|c|c|}
\hline \multirow[b]{2}{*}{ Variables } & \multicolumn{3}{|c|}{ Univariate analysis } & \multicolumn{3}{|c|}{ Multivariate analysis } \\
\hline & HR & $95 \% \mathrm{CI}$ & $\begin{array}{l}p \\
\text { value* }\end{array}$ & HR & $95 \% \mathrm{CI}$ & $\begin{array}{l}p \\
\text { value* }^{*}\end{array}$ \\
\hline Gender & & & & & & \\
\hline $\begin{array}{l}\text { Male vs. Female } \\
\text { Age (years) }\end{array}$ & 1.041 & $0.681-1.191$ & 0.854 & 1.214 & $0.657-2.242$ & 0.537 \\
\hline$<53$ vs. $\geq 53$ & 0.911 & $0.697-1.190$ & 0.492 & 1.206 & $0.818-1.778$ & 0.345 \\
\hline TNM stage & & & & & & \\
\hline $\begin{array}{l}\text { III-IV vs. I-II } \\
\text { Tumor size(cm) }\end{array}$ & 4.387 & $3.290-5.849$ & 0.000 & & & \\
\hline $\begin{array}{l}<5 \text { vs } \geq 5 \\
\text { Tumor number }\end{array}$ & 4.267 & $3.220-5.654$ & 0.000 & 4.399 & $2.838-6.817$ & 0.000 \\
\hline $\begin{array}{l}\text { Single vs. Multiple } \\
\text { Node stage }\end{array}$ & 1.853 & $1.410-2.436$ & 0.000 & 0.737 & $0.488-1.115$ & 0.149 \\
\hline N0 vs. N1-2 & 2.293 & $1.487-3.536$ & 0.000 & 1.513 & $0.753-3.040$ & 0.245 \\
\hline Distant metastases & & & & & & \\
\hline $\begin{array}{l}\text { Yes vs. No } \\
\text { BMI }(\mathrm{kg} / \mathrm{m} 2)\end{array}$ & 1.899 & $1.172-3.077$ & 0.009 & 1.211 & $0.522-2.811$ & 0.655 \\
\hline $\begin{array}{l}\geq 24.0 \text { vs. } 18.5-23.9 \text { vs. } \\
<18.5\end{array}$ & 0.793 & $0.634-0.992$ & 0.042 & 0.977 & $0.721-1.324$ & 0.880 \\
\hline Alcohol behavior & & & & & & \\
\hline Yes vs. No & 1.000 & $0.757-1.321$ & 0.999 & & & \\
\hline $\begin{array}{l}\text { Family history of } \\
\text { cancer }\end{array}$ & & & & & & \\
\hline Yes vs. No & 0.732 & $0.527-1.017$ & 0.063 & & & \\
\hline HBV DNA & & & & & & \\
\hline $\begin{array}{l}<103 \text { vs. } \geq 103 \\
\text { AFP }\end{array}$ & 2.010 & $1.349-2.993$ & 0.001 & 1.830 & $1.190-2.814$ & 0.006 \\
\hline $\begin{array}{l}<400 \text { vs. } \geq 400 \\
\text { PT }\end{array}$ & 2.066 & $1.564-2.729$ & 0.000 & 1.519 & $1.038-2.224$ & 0.031 \\
\hline $\begin{array}{l}<12.1 \text { vs. } \geq 12.1 \\
\text { APTT }\end{array}$ & 1.787 & $1.359-2.350$ & 0.000 & 1.661 & $1.125-2.451$ & 0.011 \\
\hline $\begin{array}{l}<25.6 \text { vs. } \geq 25.6 \\
\text { Fbg }\end{array}$ & 1.416 & $1.082-1.854$ & 0.011 & 1.457 & $0.982-2.161$ & 0.061 \\
\hline$<2.83$ vs. $\geq 2.83$ & 2.794 & $2.102-3.714$ & 0.000 & 2.158 & $1.427-3.263$ & 0.000 \\
\hline TT & & & & & & \\
\hline $\begin{array}{l}<18.4 \text { vs. } \geq 18.4 \\
\text { PLT }\end{array}$ & 1.009 & $0.772-1.319$ & 0.948 & & & \\
\hline$<178$ vs. $\geq 178$ & 1.850 & $1.389-2.464$ & 0.000 & 1.081 & $0.706-1.656$ & 0.720 \\
\hline
\end{tabular}

\section{Univariate and multivariate analyses of plasma hemostatic system in HCC}

To determine the prognostic value of the pre-treatment hemostatic system in HCC, the clinical characteristics (including age, gender, alcohol index, BMI, family history of cancer, pTNM status, tumor size, tumor number, node stage, distant metastases, HBV DNA, AFP) and the hemostatic system profiles were subjected to univariate and multivariate analysis. With univariate analysis, TNM stage $(P=0.000)$, tumor size $(P=0.000)$, tumor number $(P=0.000)$, node stage $(P=0.000)$, distance metastases $(P=0.009)$, BMI $(P=0.042)$, AFP $(P=0.000)$, HBV DNA $(P=0.001), \quad$ PT $\quad(P=0.000), \quad$ APTT $\quad(P=0.011), \quad$ Fbg $(P=0.000)$, and PLT $(P=0.000)$ were found to be associated with significantly overall survival (Table $2)$, also TNM stage $(P=0.000)$, tumor size $(P=0.000)$, tumor number $(P=0.000)$, node stage $(P=0.000)$, distance metastases $(P=0.010)$, BMI $(P=0.043)$, AFP $(P=0.000)$, HBV DNA $(P=0.001)$, PT $(P=0.000)$, APTT $(P=0.011), \operatorname{Fbg}(P=0.000)$, and PLT $(P=0.000)$ had effect on DFS (Table 3).

All of the potentially important parameters identified in univariate analysis were further included in the multivariate analysis, and we exclude the factors of TNM stage in the multivariate analysis because of the influence of statistical colinearity. The result showed that tumor size $(P=0.000)$, HBV DNA $(P=0.006)$, AFP $(P=0.031)$, PT $(P=0.011)$ and Fbg $(P=0.000)$ were identified as significantly independent predictors of OS of all patients (Table 2), and tumor size $(P=0.000)$, HBV DNA $(P=0.006)$, AFP $(P=0.032)$, PT $(P=0.011)$ and Fbg $(P=0.000)$ were also independent prognostic indicators of DFS (Table 3 ).

Table 3. Univariate and multivariate cox hazards analysis for Disease-free survival in 539 patients with HCC

\begin{tabular}{|c|c|c|c|c|c|c|}
\hline \multirow[b]{2}{*}{ Variables } & \multicolumn{3}{|c|}{ Univariate analysis } & \multicolumn{3}{|c|}{ Multivariate analysis } \\
\hline & HR & $95 \% \mathrm{CI}$ & $\begin{array}{l}p \\
\text { value* }^{*}\end{array}$ & HR & $95 \% \mathrm{CI}$ & $\begin{array}{l}p \\
\text { value }\end{array}$ \\
\hline Gender & & & & & & \\
\hline $\begin{array}{l}\text { Male vs. Female } \\
\text { Age (years) }\end{array}$ & 1.038 & $0.679-1.587$ & 0.863 & 1.212 & $0.656-2.240$ & 0.537 \\
\hline$<53$ vs .253 & 0.916 & $0.701-1.197$ & 0.519 & 1.207 & $0.819-1.780$ & 0.342 \\
\hline TNM stage & & & & & & \\
\hline $\begin{array}{l}\text { III-IV vs. I-II } \\
\text { Tumor size(cm) }\end{array}$ & 4.366 & $3.275-5.821$ & 0.000 & & & \\
\hline$<5$ vs $\geq 5$ & 4.247 & $3.206-5.628$ & 0.000 & 4.388 & 2.831-6.802 & 0.000 \\
\hline Tumor number & & & & & & \\
\hline $\begin{array}{l}\text { Single vs. Multiple } \\
\text { Node stage }\end{array}$ & 1.850 & $1.407-2.432$ & 0.000 & 0.738 & $0.488-1.116$ & 0.150 \\
\hline $\begin{array}{l}\text { N0 vs. N1-2 } \\
\text { Distant metastases }\end{array}$ & 2.282 & $1.480-3.519$ & 0.000 & 1.513 & $0.753-3.041$ & 0.245 \\
\hline $\begin{array}{l}\text { Yes vs. No } \\
\text { BMI }\left(\mathrm{kg} / \mathrm{m}^{2}\right)\end{array}$ & 1.893 & $1.1682-3.067$ & 0.010 & 1.212 & $0.522-2.812$ & 0.655 \\
\hline $\begin{array}{l}\geq 24.0 \text { vs. } 18.5-23.9 \text { vs. } \\
<18.5\end{array}$ & 0.794 & $0.635-0.993$ & 0.043 & 0.977 & $0.721-1.325$ & 0.881 \\
\hline Alcohol behavior & & & & & & \\
\hline $\begin{array}{l}\text { Yes vs. No } \\
\text { Family history of } \\
\text { cancer }\end{array}$ & 1.006 & $0.762-1.328$ & 0.968 & & & \\
\hline Yes vs. No & 0.729 & $0.525-1.013$ & 0.060 & & & \\
\hline HBV DNA & & & & & & \\
\hline$<10^{3}$ vs. $\geq 10^{3}$ & 2.005 & $1.346-2.987$ & 0.001 & 1.829 & $1.190-2.812$ & 0.006 \\
\hline AFP & & & & & & \\
\hline $\begin{array}{l}<400 \text { vs. } \geq 400 \\
\text { PT }\end{array}$ & 2.065 & $1.563-2.728$ & 0.000 & 1.518 & $1.037-2.222$ & 0.032 \\
\hline $\begin{array}{l}<12.1 \text { vs. } \geq 12.1 \\
\text { APTT }\end{array}$ & 1.784 & $1.357-2.346$ & 0.000 & 1.660 & $1.125-2.451$ & 0.011 \\
\hline$<25.6$ vs. $\geq 25.6$ & 1.416 & $1.082-1.854$ & 0.011 & 1.457 & $0.982-2.161$ & 0.061 \\
\hline Fbg & & & & & & \\
\hline$<2.83$ vs. $\geq 2.83$ & 2.787 & 2.096-3.705 & 0.000 & 2.161 & $1.429-3.267$ & 0.000 \\
\hline TT & & & & & & \\
\hline $\begin{array}{l}<18.4 \text { vs. } \geq 18.4 \\
\text { PLT }\end{array}$ & 1.004 & $0.768-1.313$ & 0.975 & & & \\
\hline$<178$ vs. $\geq 178$ & 1.848 & $1.387-2.462$ & 0.000 & 1.083 & 0.707-1.659 & 0.714 \\
\hline
\end{tabular}


a

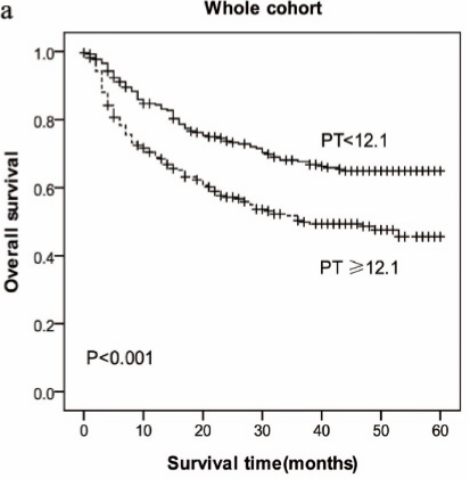

d

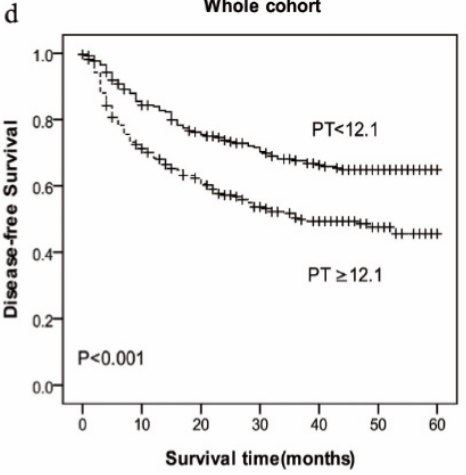

b

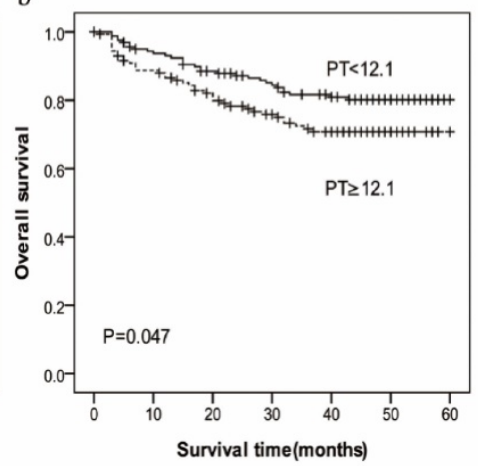

e

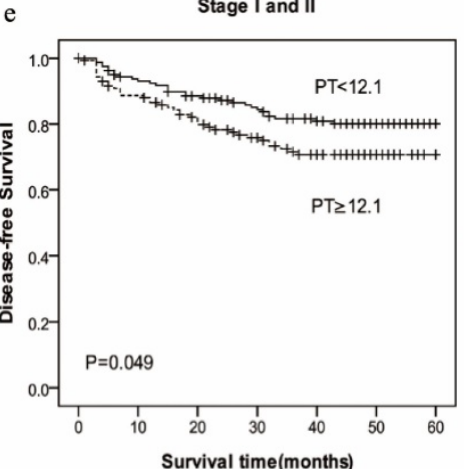

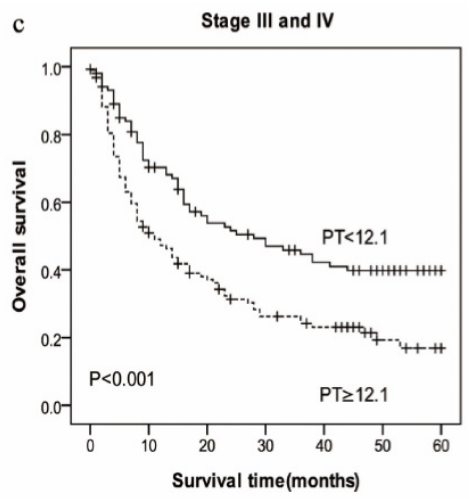

f

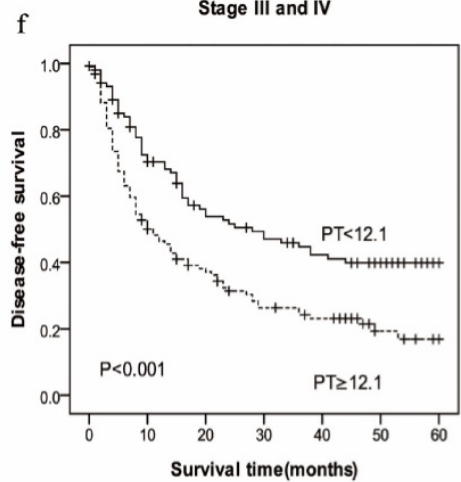

Figure 1. Prognostic significance of prolonged PT in HCC in whole cohort and different pathological stages by Kaplan-Meier survival curves. OS and DFS of HCC patients showing significantly short survival with prolonged PT not only in the entire cohort (a, d) but also in the subgroups stratified by pathological stage (stage I-II (b, e), stage III-IV (c, f)).

\section{Associations between plasma hemostatic system and HCC patients' survival}

In the Kaplan-Meier analysis, PT was closely associated with OS and DFS. Among all the HCC patients, the mean OS in high-PT group (PT $\geq 12.1 s e c$, mean: 25.75 months) was shorter than low-PT group (PT<12.1sec, mean: 35.99 months) $(\mathrm{P}=0.000)$, and the mean DFS in high-PT group (PT $\geq 12.1 \mathrm{sec}$, mean: 25.66months) also was shorter than low-PT group (PT<12.1sec, mean: 35.77 months) $(\mathrm{P}=0.000)$ (Figure 1).

Meanwhile, the mean OS in high-Fbg group ( $\mathrm{Fbg} \geq 2.83 \mathrm{~g} / \mathrm{L}$, mean: 23.88 months) was shorter than low-PT group (Fbg $<2.83 \mathrm{~g} / \mathrm{L}$, mean: 37.62 months) $(\mathrm{P}=0.000)$, and the mean DFS in high-PT group (mean: 23.76 months) also was shorter than low-PT group (mean: 37.44 months) $(\mathrm{P}=0.000)$. The results show that patients with increased PT and Fbg levels were significantly associated with shorter OS $(\mathrm{P}=0.000)$ and RFS ( $\mathrm{P}=0.000$ ) (Figure 2).

To further explore the relationship between PT and survival, we analyzed the prognostic effect of the PT level in subgroups based on the pathological stage. HCC patients with a higher PT level indicated significantly shorter OS and DFS than patients with a lower PT level in the both in stage I-II ( $\mathrm{P}=0.047$ vs. $\mathrm{P}=0.049)$ and stage III-IV ( $\mathrm{P}=0.000$ vs. $\mathrm{P}=0.000)$ subgroup, and the survival rate of patients with increased Fbg level had a significantly shorter OS and DFS compared with those patients with decreased Fbg levels both in stage I-II ( $P=0.000$ vs. $P=0.000)$ and stage III-IV subgroup ( $\mathrm{P}=0.002$ vs. $\mathrm{P}=0.002)$.

\section{The Correlation between PT, Fbg concentrations and Clinicopathologic Characteristics in HCC patients}

The associations between plasma PT, Fbg levels and clinicopathological variables in 539 HCC patients are presented in our study. The PT was associated with pathological stage and HBV DNA copies $(\mathrm{P}=0.038, \mathrm{P}=0.000$, respectively). Furthermore, all the patients were divided into two groups by the median PT (12.1sec). The PT levels were not significantly different between the two groups that were classified by age, gender, tumor size, tumor number, node stage, distant metastasis, BMI, alcohol behavior, family history of cancer, AFP. However, patients in advanced stages had longer PTs than those in the early stages of HCC $(\mathrm{P}=0.014)$, and patients with much more copies of HBV DNA also had longer PTs than those with less $(\mathrm{P}=0.000)$ (Table 4). Meanwhile, The Fbg was associated with pathological stage, tumor size, tumor number $(\mathrm{P}=0.0000, \mathrm{P}=0.000$, $\mathrm{P}=0.000$, respectively). Furthermore, all the patients were divided into two groups by the median Fbg (2.83 $\mathrm{g} / \mathrm{L}$ ). The Fbg levels were not significantly different 

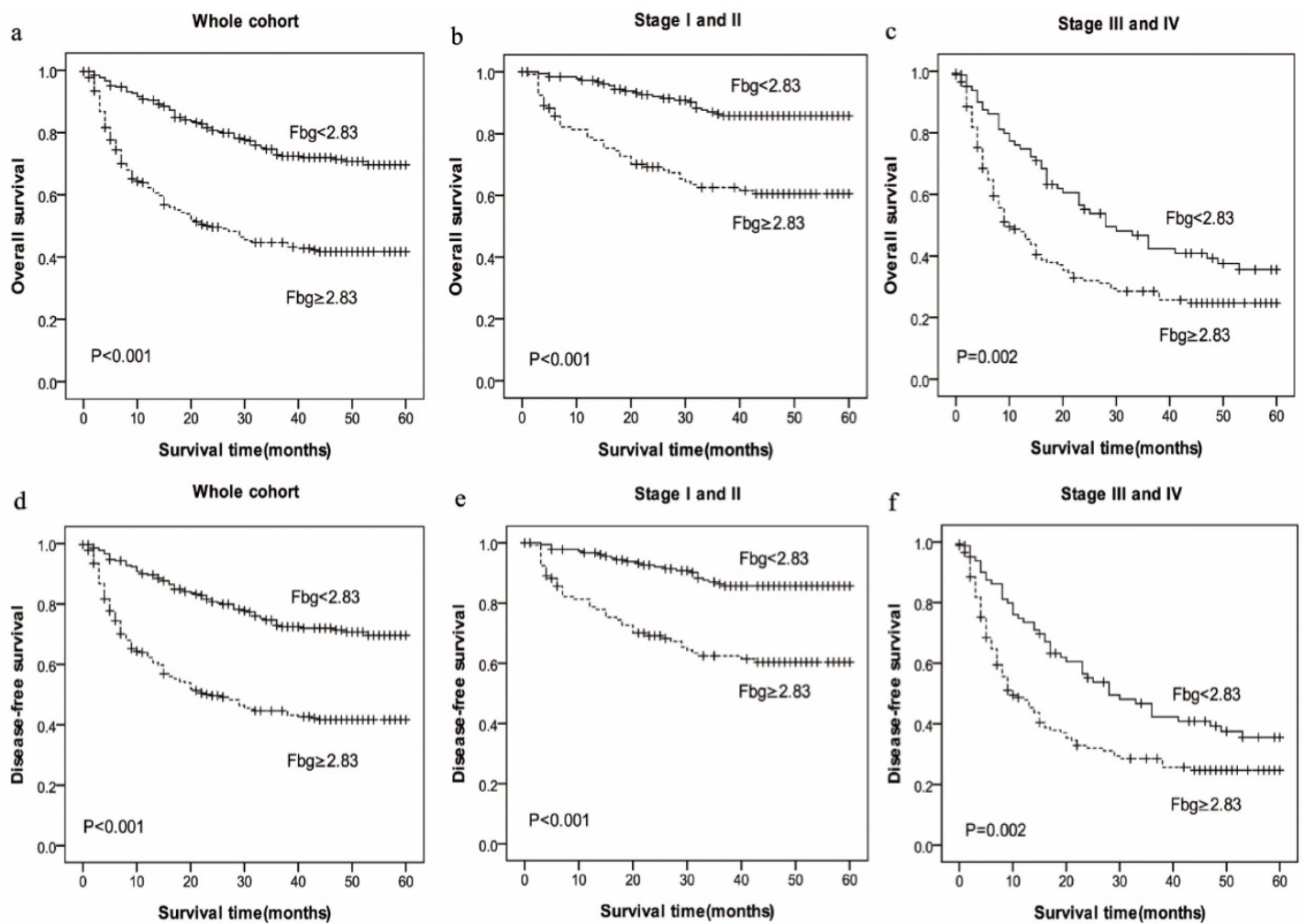

Figure 2. Prognostic significance of increased Fbg levels in HCC in whole cohort and different pathological stages by Kaplan-Meier survival curves. OS and DFS of HCC patients showing significantly short survival with increased Fbg levels not only in the entire cohort (a, d) but also in the subgroups stratified by pathological stage (stage I-II(b, e), stage III-IV(c, f) ).

between the two groups that were classified by age, gender, distant metastasis, BMI, alcohol behavior, family history of cancer, HBV DNA copies, AFP. However, patients in advanced stages had higher Fbg levels than those in early stages of HCC $(\mathrm{P}=0.000)$ (Table 5).

\section{A Novel hemostatic-Based Stage Predicts Overall Survival and of Patients with HCC}

The prolonged PT and increased Fbg concentrations, which reflects poor OS and DFS of HCC, were prompted to develop a prognostic grouping system and evaluate the prognostic significance in HCC. Patients were assigned as follows: group 1 (low risk: $\mathrm{PT}<12.1 \mathrm{sec}$ and $\mathrm{Fbg}<2.83 \mathrm{~g} / \mathrm{L}$ ), group 2 (medium risk: $\mathrm{PT} \geq 12.1 \mathrm{sec}$ or $\mathrm{Fbg} \geq 2.83 \mathrm{~g} / \mathrm{L}$ ), group 3 (high risk: $\mathrm{PT} \geq 12.1 \mathrm{sec}$ and $\mathrm{Fbg} \geq 2.83 \mathrm{~g} / \mathrm{L}$ ). There were 139 (25.84\%) allocated in group 1, 254 $(47.21 \%)$ allocated in group 2, and 145 (26.95\%) allocated in group 3. The 5-year OS for HCC patients in group 1, group 2 and group 3 were $(41.37 \pm 17.76)$ months, $(31.83 \pm 19.84)$ months, $(18.68 \pm 18.41)$ months, respectively ( $\mathrm{P}=0.000$, Figure 3$)$, and the 5 -year DFS for HCC patients in group 1, group 2 and group 3 were $(41.15 \pm 17.88)$ months, $(31.65 \pm 19.81)$ months, (18.66 \pm 18.39$)$ months, respectively $(\mathrm{P}=0.000$, Figure 3$)$.

\section{Discussion}

Hepatocellular carcinoma is a heterogeneous solid tumor affecting the main detoxifying organ in our body. And the treatment selection is tough because no diagnostic tool has been developed to detect HCC in its early stages, which lead to a short OS and DFS. Therefore, prognostic biomarkers are needed in understanding the development of cancer and choosing individual therapeutic strategies. Thus, it is urgent to find inexpensive and convenient prognostic biomarkers for this disease.

Coagulation parameters are routine laboratory tests, which are widely used to detect the function of coagulation, anticoagulation and fibrinolytic system. And many earlier investigations have noted the relationship between coagulation parameters and the prognostic significance of malignances. A systematic activation of clotting system has been observed in cancer patients which is usually reflected by subclinical abnormalities of conventional coagulation tests [15]. In this study, we defined the cut-off value of PT and Fbg as the median, and demonstrated that pretreatment plasma PT and Fbg levels were associated with OS and DFS in HCC patients. In this retrospective study, we observed that patients with increased PT levels had significantly shorter OS and DFS compared with those patients with decreased PT 
levels, not only in the entire cohort (HR: $1.661,95 \% \mathrm{CI}$ : 1.125-2.451, $p=0.011$ vs. HR: $1.660,95 \% \mathrm{CI}: 1.125-2.451$, $p=0.011$ ) but also in the subgroups stratified by pathological stage (stage I-II and stage III-IV). We also found that patients with a higher Fbg experienced significantly shorter OS and DFS than patients with a lower Fbg, not only in the entire cohort (HR: 2.158, 95\%CI: $1.427-3.263, p<0.001$ vs. HR: $2.161,95 \% \mathrm{CI}$ : 1.429-3.267, $p<0.001)$, but also in the subgroups stratified by pathological stage (stage I-II and stage III-IV). Therefore, PT and Fbg are the independent risk factors for HCC prognosis. Our evidence shows that with advanced HCC pathological stage, the coagulation parameters were more impaired: patients with advanced HCC exhibited longer PT levels than patients with early-stage disease in the current study; Higher Fbg was found to be positively correlated with pathological stage, tumor size, tumor number, node metastasis in HCC.

Table 4. Relationship between the PT levels and the clinical characteristics in patients with HCC

\begin{tabular}{|c|c|c|c|c|c|c|}
\hline \multirow[t]{2}{*}{ Characteristics } & \multicolumn{6}{|l|}{ PT } \\
\hline & Cases(n) & $<12.1$ & $\geq 12.1$ & $p$ value $^{*}$ & Mean \pm SD & $p$ value ${ }^{* *}$ \\
\hline \multicolumn{7}{|l|}{ Gender } \\
\hline Male & 479 & 231 & 248 & 0.383 & $12.25 \pm 1.13$ & 0.079 \\
\hline Female & 59 & 32 & 27 & & $12.03 \pm 1.33$ & \\
\hline \multicolumn{7}{|l|}{ Age (years) } \\
\hline$\geq 53$ & 275 & 132 & 143 & 0.675 & $12.27 \pm 1.16$ & 0.433 \\
\hline$<53$ & 263 & 131 & 132 & & $12.36 \pm 1.16$ & \\
\hline \multicolumn{7}{|l|}{ Stage } \\
\hline I and II & 305 & 161 & 144 & 0.038 & $12.13 \pm 1.14$ & 0.014 \\
\hline III and IV & 233 & 102 & 131 & & $20.87 \pm 20.07$ & \\
\hline \multicolumn{7}{|l|}{ Tumor size(cm) } \\
\hline$\geq 5$ & 220 & 98 & 122 & 0.094 & $12.35 \pm 1.17$ & 0.033 \\
\hline$<5$ & 318 & 165 & 153 & & $12.14 \pm 1.14$ & \\
\hline \multicolumn{7}{|l|}{ Tumor number } \\
\hline Single & 335 & 168 & 167 & 0.748 & $12.20 \pm 1.13$ & 0.770 \\
\hline Multiple & 192 & 93 & 98 & & $12.23 \pm 1.15$ & \\
\hline \multicolumn{7}{|l|}{ Node stage } \\
\hline No & 501 & 246 & 255 & 0.711 & $12.22 \pm 1.13$ & 0.659 \\
\hline N1-2 & 37 & 17 & 20 & & $12.38 \pm 1.39$ & \\
\hline \multicolumn{7}{|c|}{ Distant metastases } \\
\hline Yes & 31 & 14 & 17 & 0.677 & $12.42 \pm 1.28$ & 0.454 \\
\hline No & 507 & 248 & 258 & & $12.22 \pm 1.15$ & \\
\hline \multicolumn{7}{|l|}{ BMI $\left(\mathrm{kg} / \mathrm{m}^{2}\right)$} \\
\hline$\geq 24.0$ & 174 & 91 & 83 & 0.000 & $12.19 \pm 1.21$ & 0.156 \\
\hline $18.5-23.9$ & 318 & 152 & 166 & & $12.21 \pm 1.13$ & \\
\hline$<18.5$ & 45 & 19 & 26 & & $12.49 \pm 1.10$ & \\
\hline \multicolumn{7}{|l|}{ Alcohol behavior } \\
\hline Yes & 199 & 97 & 102 & 0.96 & $12.17 \pm 1.15$ & 0.358 \\
\hline No & 339 & 166 & 173 & & $12.26 \pm 1.16$ & \\
\hline \multicolumn{7}{|l|}{$\begin{array}{l}\text { Family history of } \\
\text { cancer }\end{array}$} \\
\hline Yes & 138 & 69 & 69 & 0.761 & $12.15 \pm 1.08$ & 0.516 \\
\hline No & 400 & 194 & 206 & & $12.26 \pm 1.18$ & \\
\hline \multicolumn{7}{|l|}{$\begin{array}{l}\text { HBV DNA } \\
\text { (copies/mL) }\end{array}$} \\
\hline$\geq 10^{3}$ & 280 & 121 & 159 & 0.000 & $12.36 \pm 1.10$ & 0.000 \\
\hline$<10^{3}$ & 128 & 81 & 47 & & $11.81 \pm 1.03$ & \\
\hline \multicolumn{7}{|l|}{$\operatorname{AFP}(\mathrm{ng} / \mathrm{mL})$} \\
\hline$\geq 400$ & 194 & 88 & 106 & 0.125 & $12.35 \pm 1.12$ & 0.018 \\
\hline$<400$ & 323 & 169 & 154 & & $12.13 \pm 1.11$ & \\
\hline
\end{tabular}

Mean \pm SD, Mean \pm standard deviation.

${ }^{*} \mathrm{P}$ values were calculated using the chi-squared test $\left(\mathrm{X}^{2}\right.$ test), $p<0.05$ indicated significant differences.

**P values were calculated using unpaired Student's t-tests or Mann-Whitney U test, $p<0.05$ indicated significant differences.
Table 5. Relationship between the Fbg levels and the clinical characteristics in patients with $\mathrm{HCC}$

\begin{tabular}{|c|c|c|c|c|c|c|}
\hline \multirow[t]{2}{*}{ Characteristics } & \multicolumn{6}{|c|}{ Fbg } \\
\hline & Cases(n) & $<2.83$ & $\geq 2.83$ & $\begin{array}{l}p \\
\text { value* }\end{array}$ & $\begin{array}{l}\text { Mean } \pm \\
\text { SD }\end{array}$ & $\begin{array}{l}p \\
\text { value* }\end{array}$ \\
\hline \multicolumn{7}{|l|}{ Gender } \\
\hline Male & 479 & 246 & 233 & 0.073 & $3.20 \pm 1.21$ & 0.371 \\
\hline Female & 59 & 23 & 36 & & $3.21 \pm 1.06$ & \\
\hline \multicolumn{7}{|l|}{ Age (years) } \\
\hline$\geq 53$ & 275 & 132 & 143 & 0.000 & $3.24 \pm 1.25$ & 0.253 \\
\hline$<53$ & 263 & 137 & 126 & & $3.13 \pm 1.13$ & \\
\hline \multicolumn{7}{|l|}{ Stage } \\
\hline I and II & 305 & 185 & 120 & 0.000 & $2.90 \pm 1.06$ & 0.000 \\
\hline III and IV & 233 & 84 & 149 & & $3.55 \pm 1.26$ & \\
\hline \multicolumn{7}{|l|}{ Tumor size $(\mathrm{cm})$} \\
\hline$\geq 5$ & 220 & 77 & 143 & 0.000 & $3.58 \pm 1.27$ & 0.000 \\
\hline$<5$ & 318 & 192 & 126 & & $2.91 \pm 1.05$ & \\
\hline \multicolumn{7}{|l|}{ Tumor number } \\
\hline Single & 335 & 189 & 146 & 0.000 & $3.04 \pm 1.14$ & 0.000 \\
\hline Multiple & 191 & 77 & 114 & & $3.39 \pm 1.23$ & \\
\hline \multicolumn{7}{|l|}{ Node stage } \\
\hline No & 501 & 256 & 245 & 0.061 & $3.16 \pm 1.20$ & 0.044 \\
\hline N1-2 & 37 & 13 & 24 & & $3.45 \pm 1.07$ & \\
\hline \multicolumn{7}{|c|}{ Distant metastases } \\
\hline Yes & 31 & 15 & 16 & 0.853 & $3.26 \pm 1.20$ & 0.709 \\
\hline No & 507 & 254 & 253 & & $3.18 \pm 1.19$ & \\
\hline \multicolumn{7}{|l|}{ BMI $\left(\mathrm{kg} / \mathrm{m}^{2}\right)$} \\
\hline$\geq 24.0$ & 174 & 95 & 79 & 0.319 & $3.15 \pm 1.20$ & 0.671 \\
\hline $18.5-23.9$ & 318 & 152 & 166 & & $3.19 \pm 1.19$ & \\
\hline$<18.5$ & 45 & 21 & 24 & & $3.29 \pm 1.19$ & \\
\hline \multicolumn{7}{|c|}{ Alcohol behavior } \\
\hline Yes & 199 & 103 & 96 & 0.532 & $3.24 \pm 1.29$ & 0.791 \\
\hline No & 339 & 166 & 173 & & $3.15 \pm 1.13$ & \\
\hline \multicolumn{7}{|l|}{$\begin{array}{l}\text { Family history of } \\
\text { cancer }\end{array}$} \\
\hline Yes & 138 & 71 & 67 & 0.693 & $3.15 \pm 1.19$ & 0.524 \\
\hline No & 400 & 198 & 202 & & $3.19 \pm 1.19$ & \\
\hline \multicolumn{7}{|l|}{$\begin{array}{l}\text { HBV DNA } \\
\text { (copies/mL) }\end{array}$} \\
\hline$\geq 10^{3}$ & 280 & 139 & 141 & 0.275 & $3.18 \pm 1.18$ & 0.886 \\
\hline$<10^{3}$ & 128 & 71 & 57 & & $3.19 \pm 1.35$ & \\
\hline \multicolumn{7}{|l|}{$\operatorname{AFP}(n g / m L)$} \\
\hline$\geq 400$ & 194 & 93 & 101 & 0.271 & $3.23 \pm 1.16$ & 0.181 \\
\hline$<400$ & 323 & 171 & 152 & & $3.15 \pm 1.24$ & \\
\hline \multicolumn{7}{|c|}{$\begin{array}{l}\text { Mean } \pm S D, \text { Mean } \pm \text { standard deviation. } \\
* P \text { values were calculated using the chi-squared test }\left(\chi^{2} \text { test }\right), p<0.05 \text { indicated } \\
\text { significant differences. }\end{array}$} \\
\hline
\end{tabular}

The PT and Fbg tests are widely used in clinical laboratories to demonstrate the abnormal coagulation and fibrinolysis system. The system consists of extrinsic and intrinsic coagulation cascades, which could activate the prothrombin to thrombin, and formatted the fibrin clot. Meanwhile, the fibrin clot was lysed by the activated fibrinolysis system. And the associations between coagulation system and cancer have been frequently studied [16]. First of all, many studies have demonstrated that coagulation system has an effect on the solid tumors, such as ESCC [10], penile cancer [17], HCC [18], lung cancer [11] and so on. Secondly, hematological system diseases have been reported related to this [19, 20]. The last, Zhu et. suggested that abnormal coagulation 
a

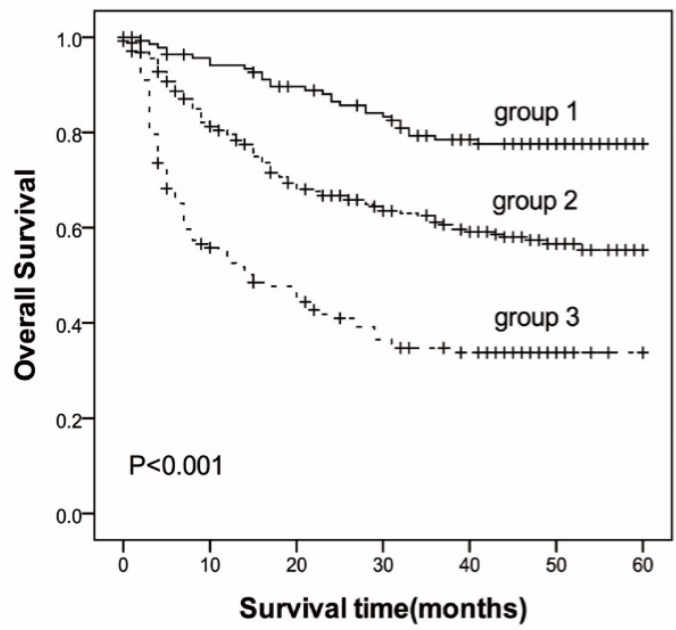

b

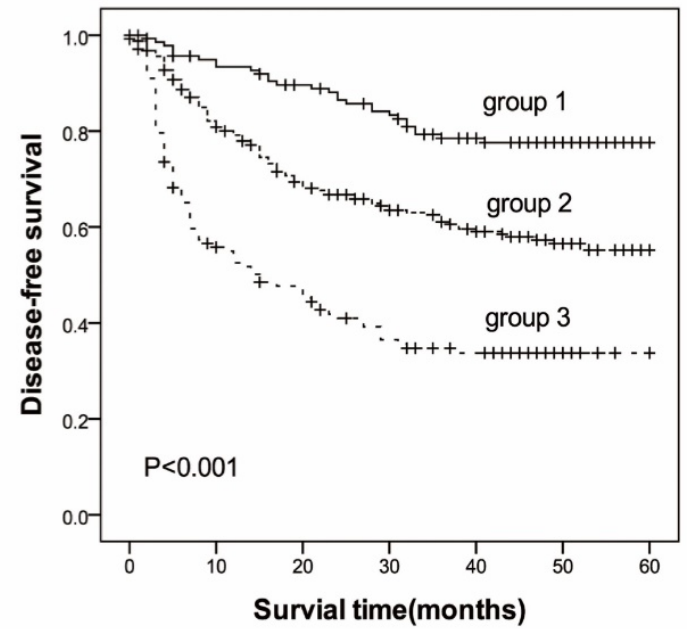

Figure 3. Patients with HCC were divided into three group by incorporating two independent prognostic variables (PT and Fbg). Group 1(low risk: $\mathrm{PT}<12.1 \mathrm{sec}$ and $\mathrm{Fbg}<2.83 \mathrm{~g} / \mathrm{L}$ ), group 2(medium risk: $\mathrm{PT} \geq 12.1 \mathrm{sec}$ or $\mathrm{Fbg} \geq 2.83 \mathrm{~g} / \mathrm{L}$ ), group 3(high risk: $\mathrm{PT} \geq 12.1 \mathrm{sec}$ and $\mathrm{Fbg} \geq 2.83 \mathrm{~g} / \mathrm{L}$ ).

system was an independent prognostic factor for the brain metastases of NSCLC [21]. But, the function of coagulation and fibrinolysis system in carcinogenesis is complex and not well understood, which might be involved in advanced age, tumor-inflammatory activity, and cancer treatment (including chemotherapeutic agents, hormonal therapy, operative treatment).

As we all known, the liver is a vital organ of the body metabolism, which is play an important role in synthesizing clotting factors. Liver cells is damaged by various diseases, especially in patients with liver cancer, which lead to the reduction of protein synthesis including clotting factors, and the function of removal of tissue coagulation enzymes and fibrinolytic factors declined [21]. Furthermore, tumor cells directly, produce various procoagulant activities (PCAs) and proinflammatory cytokines, among which, the best defined are the tissue factor (TF), the cancer procoagulant $(\mathrm{CP})$, tumor necrosis factor (TNF-a), interleukin-1 (IL-1b) and vascular endothelial growth factor (VEGF). TF known as coagulation factor III, is a transmembrane glycoprotein, which comprise complex with factor VII, activating the extrinsic pathway of blood coagulation. Overexpression of TF in the blood of cancer patients not only originates from monocytes and other host cells, but also directly synthesized and released from malignant cells [23], which supports tumor metastatic development and dissemination [24]. CP known as a cysteine proteinase, which exhibits procoagulant activity through directly activating factor $X$ and is found principally in malignant tissues [25], but the precise role that $\mathrm{CP}$ plays in mediating the hypercoagulable state in malignancy remains speculative. TNF- $\alpha$, IL-1 $\beta$ and VEGF are proinflam- matory cytokines, in which, TNF- $\alpha$ and IL-1 $\beta$ are play a role in reducing activation of the $C$ protein system, one of the principal endogenous anticoagulant defense systems [26]. And the VEGF could be influenced by TF, is associated with tumor neovascularization [27]. That is to say, the imbalance of tumor, coagulation and inflammation, not only function of blood coagulation disorders, but also promote the growth of tumor invasion and metastasis.

For prolonged $\mathrm{PT}$, the exact mechanisms underlying the association remains unclear, some possible explanations as follows: Firstly, PT prolongation reflected the biosynthetic capacity of the liver, hepatic insufficiency may lead to decreased the coagulation factors (including FXIII, FX, FV and so on) in plasma, and hepatic congestion might also affect the production of coagulation factors; Secondly, activation of the coagulation system may result in consumption of coagulation factors. The increased inflammation and activated neurohormonal activity in tumor microenvironment, have been previously suggested to cause activated coagulation in HCC patients [28]; Thirdly, some specific inhibitor of coagulation factors and lots of fibrin split products have been produced by tumor, which could delay the fibrin formation. Fbg is recognized as multiple integrin and nonintegrin receptors among tumor cells, stromal cells and inflammatory cells. The cellular interactions of $\mathrm{Fbg}$ mediated by specific receptors function as control cell proliferation, cell migration, apoptosis, and the expression of inflammatory mediators. Fbg may also play a major role in tumor metastasis, though the mechanism remains unclear [29]. The associations between increased Fbg and cancer, several potential mechanisms have been postulated: 1 . The function of synthesizing fibrinolytic 
enzyme inhibitor and removing of fibrin degradation products was damaged; 2 . In blood circulation, the tumor cells, endothelial cells and platelets interacted with each other, which activated the platelets through releasing various bioactive substances, and the molecules in platelets particle, such as Fbg, may dilute into the blood circulation to participate in tumor metastasis [29]; 3. The natural killer cytotoxicity with thrombin was blocked by Fbg layers, which can protect tumor cells from the innate immune system [32].

In summary, to our knowledge, this is the retrospective study investigating the relationship between pre-therapy plasma coagulation system and HCC. Based on the 539 patients, our study provides strong evidence supporting that pretreatment plasma PT and Fbg levels are prognostic factors for OS and DFS in HCC, both in the entire cohort and in groups stratified by pathological stage, which presents a high reproducibility and it can easily be measured in all diagnostic laboratories. As this study is a retrospective analysis, it is only valid for generating hypotheses and the value of PT and Fbg should be validated in larger prospective trials.

\section{Abbreviations}

HCC: Hepatocellular carcinoma; OS: overall survival; DFS: disease-free survival; AFP: a-fetoprotein; GGT: $\gamma$-glutamyl transferase; CEA: carcino-embryonic antigen; PT: Prothrombin time; APTT: activated partial thromboplastin time; TT: thrombin time; Fbg: fibrinogen; INR: international normalized ratio.

\section{Acknowledgement}

We thank the staff of the biochemical lab of Sun Yat-sen University Cancer Center, who provided various biochemical markers, and all the staff who supported our study.

\section{Authors' contributions}

Xueping Wang and Minjie Mao carried out the main work and contributed equally. They participated in the design of the study and drafted the manuscript. Lin Zhang and Peidong Chi performed the statistical analysis. Wanli Liu and Shuqin Dai conceived the study and participated in its design and coordination, Zhonglian He and Jiarui Su helped to draft the manuscript. All authors read and approved the final manuscript.

\section{Competing Interests} interests.

\section{References}

1. Llovet JM, Burroughs A, Bruix J. Hepatocellular carcinoma. Lancet. 2003; 362: 1907-1917.

2. El-Serag HB, Mason AC. Rising incidence of hepatocellular carcinoma in the United States. N Engl J Med. 1999; 340: 745-750.

3. Kabbach G, Assi HA, Bolotin G et al. Hepatobiliary Tumors: Update on Diagnosis and Management. J Clin Transl Hepatol. 2015; 3: 169-181.

4. Liu J, Xia Y, Shi L et al. Elevated Serum Carcinoembryonic Antigen Is Associated with a Worse Survival Outcome of Patients After Liver Resection for Hepatocellular Carcinoma: a Propensity Score Matching Analysis. J Gastrointest Surg. 2016; 20: 2063-2073.

5. Loreto MF, De Martinis M, Corsi MP et al. Coagulation and cancer: implications for diagnosis and management. Pathol Oncol Res. 2000; 6: 301-312.

6. Amirkhosravi A, Meyer T, Amaya M et al. The role of tissue factor pathway inhibitor in tumor growth and metastasis. Semin Thromb Hemost. 2007; 33: 643-652.

7. Langer F, Holstein K, Eifrig B, Bokemeyer C. [Haemostatic aspects in clinical oncology]. Hamostaseologie. 2008; 28: 472-480.

8. Falanga A, Marchetti M, Vignoli A, Balducci D. Clotting mechanisms and cancer: implications in thrombus formation and tumor progression. Clin Adv Hematol Oncol. 2003; 1: 673-678.

9. McAlister RK, Ito S. Minimal Prolongation of Prothrombin Time with Extended Exposure to Argatroban. Pharmacotherapy. 2015; 35: e122-e126.

10. Li XH, Wang XP, Gu WS et al. Clinical Significance of Preoperative Thrombin Time in Patients with Esophageal Squamous Cell Carcinoma following Surgical Resection. PLoS One. 2015; 10: e140323.

11. Tas F, Kilic L, Serilmez M et al. Clinical and prognostic significance of coagulation assays in lung cancer. Respir Med. 2013; 107: 451-457.

12. Bottasso B, Mari D, Coppola R et al. Hypercoagulability and hyperfibrinolysis in patients with melanoma. Thromb Res. 1996; 81: 345-352.

13. Shu YJ, Weng $H$, Bao RF et al. Clinical and prognostic significance of preoperative plasma hyperfibrinogenemia in gallbladder cancer patients following surgical resection: a retrospective and in vitro study. BMC Cancer. 2014; 14: 566.

14. Vlodavsky I, Ilan N, Nadir $Y$ et al. Heparanase, heparin and the coagulation system in cancer progression. Thromb Res. 2007; 120 Suppl 2: S112-S120.

15. Falanga A. Thrombophilia in cancer. Semin Thromb Hemost. 2005; 31: 104-110.

16. Prandoni $P$, Lensing AW, Buller HR et al. Deep-vein thrombosis and the incidence of subsequent symptomatic cancer. N Engl J Med. 1992; 327: 1128-1133.

17. Ma C, Zhou $Y$, Zhou S et al. Preoperative peripheral plasma fibrinogen level is an independent prognostic marker in penile cancer. Oncotarget. 2016.

18. Gao $\mathrm{H}$, Zhu F, Wang $\mathrm{M}$ et al. Preoperatively staging liver fibrosis using noninvasive method in Hepatitis B virus-infected hepatocellular carcinoma patients. Oncotarget. 2016.

19. Bottasso B, Mari D, Coppola R et al. Hypercoagulability and hyperfibrinolysis in patients with melanoma. Thromb Res. 1996; 81: 345-352.

20. Ghosh BC, Cliffton EE. Malignant tumors with superior vena cava obstruction. N Y State J Med. 1973; 73: 283-289.

21. Zhu JF, Cai L, Zhang XW et al. High plasma fibrinogen concentration and platelet count unfavorably impact survival in non-small cell lung cancer patients with brain metastases. Chin J Cancer. 2014; 33: 96-104.

22. Aytac S, Turkay C, Bavbek N, Kosar A. Hemostasis and global fibrinolytic capacity in chronic liver disease. Blood Coagul Fibrinolysis. 2007; 18: 623-626.

23. Rak J, Milsom C, May L et al. Tissue factor in cancer and angiogenesis: the molecular link between genetic tumor progression, tumor neovascularization, and cancer coagulopathy. Semin Thromb Hemost. 2006; 32: 54-70.

24. Francis JL, Biggerstaff J, Amirkhosravi A. Hemostasis and malignancy. Semin Thromb Hemost. 1998; 24: 93-109.

25. Donati MB, Gambacorti-Passerini C, Casali B et al. Cancer procoagulant in human tumor cells: evidence from melanoma patients. Cancer Res. 1986; 46: 6471-6474.

26. Dittman WA, Majerus PW. Structure and function of thrombomodulin: a natural anticoagulant. Blood. 1990; 75: 329-336.

27. Mackman N. Role of tissue factor in hemostasis and thrombosis. Blood Cells Mol Dis. 2006; 36: 104-107.

28. Cugno M, Mari D, Meroni PL et al. Haemostatic and inflammatory biomarkers in advanced chronic heart failure: role of oral anticoagulants and successful heart transplantation. Br J Haematol. 2004; 126: 85-92.

29. Jones JM, McGonigle NC, McAnespie M et al. Plasma fibrinogen and serum C-reactive protein are associated with non-small cell lung cancer. Lung Cancer. 2006; 53: 97-101.

30. Jones JM, McGonigle NC, McAnespie M et al. Plasma fibrinogen and serum C-reactive protein are associated with non-small cell lung cancer. Lung Cancer. 2006; 53: 97-101.

31. Palumbo JS, Kombrinck KW, Drew AF et al. Fibrinogen is an important determinant of the metastatic potential of circulating tumor cells. Blood. 2000; 96: 3302-3309.

32. Zheng $S$, Shen $J$, Jiao $Y$ et al. Platelets and fibrinogen facilitate each other in protecting tumor cells from natural killer cytotoxicity. Cancer Sci. 2009; 100: 859-865. 